
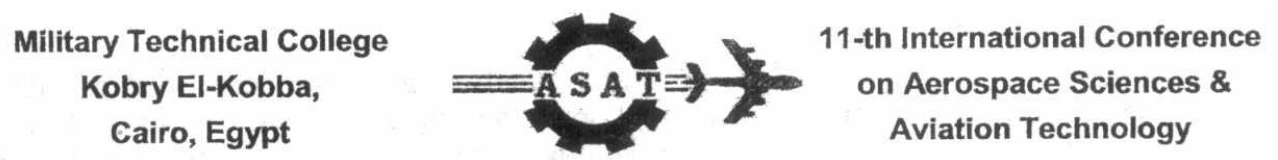

\title{
BALLISTIC RESISTANCE OF FLEXIBLE COMPOSITE (KEVLAR-129/LINE-X xs 350)
}

\author{
A. Fayed ${ }^{*}$, E. Elawad ${ }^{*}$, and M. S. Abdelkader**
}

\begin{abstract}
The use of textile and flexible composites for the containment of high-speed fragmentation is well established; the design of body armour, fragmentation curtains and bomb blankets are end products, routinely deployed. In this paper an experimental program is conducted to test a new composite material of (3Dweave $^{\text {TM }}$ Kevlar-129/ LINE-X xs-350), which is a two-component spray-in-place flexible $100 \%$ solids Polyurea/Polyurethane system. Ballistic response of this new composite is compared to that of (3D-weave $\left.{ }^{T M}\right)$ Kevlar-129; the multilayered targets of the two materials are subjected to impact by $7.62 \times 39 \mathrm{~mm}$ normal projectiles in the velocity range of $300-450 \mathrm{~m} / \mathrm{s}$. The average energy absorbed per one layer of the new composite and Kevlar targets is calculated. Calculations show that the composite targets are generally more efficient than the Kevlar targets in defeating impacting projectiles. Moreover, post firing examination of Kevlar/line-x targets shows recoverable behaviour and localized damage after the ballistic impact; this means small trauma effect in case of using this composite as body armour.
\end{abstract}

\section{INTRODUCTION}

When subjected to ballistic impact loading, polymer textile composites resist the impact by absorbing the projectile's kinetic energy as both target material kinetic energy and strain energy. The following reviews previous work in the filed of penetration of textile and composite materials.

Leech, et al [1] introduced a modelization of the arrest of high speed projectiles by orthogonally woven cloth and nets obtained by using a variational principle. Their work based on the idea of the wave front generated by a localized impact on orthogonally woven cloth and dense nets was theoretically shown to be rhomboidal. They obtained an approximate solution for the behavior of both linear (small deflection) and non-linear (large deflection) systems.

* Egyptian Armed Forces.

** Prof., Arab Academy for Science, Technology and Maritime Transport. 
Gouqi Zhu, et al [2] studied quasi-static and dynamic penetration of cylindroconical projectiles into composite targets consisting of woven Kevlar 29 fiber plies in a thermosetting polyester matrix curing at room temperature. In the quasi-static test a closed loop servo hydraulic testing system using load cell with a capacity of $400 \mathrm{kN}$ was used. Penetrators consisted of hard steel cylindrical projectiles with diameter of $12.7 \mathrm{~mm}$ and conical or blunt tip. Cone angles employed were $60^{\circ}, 90^{\circ}$, and $120^{\circ}$. The dynamic penetration tests utilized 12.7 $\mathrm{mm}$ and $9.5 \mathrm{~mm}$ diameter cylindro-conical steel projectiles with $60^{\circ}$ tip angle and mass of 28.9 and $15.4 \mathrm{~g}$, respectively.

Shim, et al [3] examined the dynamic mechanical properties of Twaron fabric via high-speed tensile tests on specimens using a split Hopkinson bar. The loaddeformation and failure characteristics at different rates of stretching were determined, from which constitutive equations representing its viscoelasticity and strain-rate dependence were formulated. This facilitated modeling of the material response to impact and perforation. Experimental results indicated that Twaron is highly strain-rate dependent; the tensile strength and modulus increase with strain rate while the failure strain decreases. Twaron specimens were also observed to fail in a more brittle fashion as the strain rate increases; this phenomenon significantly reduces the amount of energy absorbed at high strain rates.

Walker [4] examined the ballistic limit of fabric sheets with the equivalent areal density of fabric/resin composite. It is shown that for low relative area densities of fabric, the loss in fabric material (by weight) by adding resin leads to the loss in performance of the armor system. However, as the relative areal density increases, the fabric/resin composite panel begins to show bending stiffness, and its performance increases. Experimentally it has been observed that the cross over in performance is in the region where the mass of fabric material involved in the momentum balance equals the mass of the impacting bullet. As the areal density of the fabric increases beyond this point, the ballistic resistance of fabric/resin composite panel becomes better than that of a dry fabric with equivalent areal density.

DeLuca, et at [5], tested different sizes of S2-glass-fabric-reinforced plastic (GFRP) laminate plates ballistically by impacting them with two different sizes of fragment simulating projectiles at various velocities below the limiting velocity of perforation. The impacted specimens were examined with computed tomography to determine the extent of damage in the specimens, and then those specimens were tested in compression until failure. Laminates were made of S2-glass woven roving in polyester resin matrix with resin content $32 \%$ by weight. All targets were made of GFRP panel $20 \times 20 \mathrm{~mm}$ in size, and were rigidly fixed. Tests were conducted with fragment simulators of mass 13.4 grams, $12.7 \mathrm{~mm}$ caliber, and 53.8 grams, $20 \mathrm{~mm}$ caliber at normal impact. 
Billon and Robinson [6] presented two numerical models and an analytical model for assessing the ballistic performance of multi-layer fabrics of different types, and the model predictions were compared with experimental results. Projectiles used were of caliber 5.59 and $7.62 \mathrm{~mm}$ with velocities ranging from $200-750 \mathrm{~m} / \mathrm{s}$. Tested fabrics were ballistic nylon, high modulus polyethylene (HMPE), and aramid. The models had a good agreement with the experimental results of the two types of fabrics.

Fayed, et al [7], studied normal perforation of a small caliber projectile into textile lepoxy composite targets. They used a Kevlar-129 and S-2 glass textiles for manufacturing the composite which had a new weave shape (3D weave ${ }^{T M}$ ). Tests were performed to determine their mechanical properties and an analytical model was presented to describe the penetration process and to evaluate their ballistic resistance against small caliber projectiles. Experimental results were compared with model predictioris; good agreement was generally obtained. Results show that the tested composites have a limited ballistic resistance.

The present work encompasses the following main objectives:

- To study experimentally the ballistic resistance of multi-layer (3D weave ${ }^{T M}$ ) Kevlar-129 fabric impacted with $7.62 \mathrm{~mm}$ projectile with different impact velocities, thus showing the effect of projectile impact velocity and number of layers on the ballistic resistance of composite.

- To construct a flexible composite target using LINE-X (xs 350 type) polymer and the Kevlar-129 fabric and find out how the ballistic resistance compares to that of the Kevlar-129 fabric alone.

\section{EXPERIMENTAL WORK}

In general, the scheme of the experimental work performed in this study included the following phases: i) Target material choice and preparation, ii) Material characterization, iii) Ballistic tests and measurements, and iv)Post-firing examinations.

\section{Target Material Choice and Preparation}

The polymeric composite used in this study consists of Polyurea/Polyurethane P.P. polymer, reinforced by (3D weave ${ }^{T M}$ ) Kevlar-129 textile. It was chosen because it has high energy absorption during failure, which makes it ideal for ballistic protection. It also has low density, high strength-to-weight ratio, and high modulus-to-weight ratios.

LINE-X XS-350 is a two-component spray-in-place flexible $100 \%$ solids Polyurea/Polyurethane system. It is designed for processing through LINE-X dispensing equipment. It is fast-set and fast-cure material. It also exhibits excellent adhesion to most materials including steel, concrete, wood, fiber glass, and Kevlar. LINE-X is suitable as a protective abrasive impact liner for pipelines, tanks, industrial floors, sea water vessels, helicopter decks, and proved for blast mitigation [8]. In this study it was tested for improving the ballistic resistance. It 
has high resistance to sun ultra violet radiation and severe weather conditions. It has low density and outstanding abrasion resistance, impact strength, tensile strength, tear strength and high elongation percent. Table (1) lists the mechanical properties of the LINE-X XS-350 [8]. Figure (1) illustrate the microscopic photography of produced composite.

Table (1) Mechanical properties of LINE-X XS-350[8].

\begin{tabular}{|c|c|}
\hline Properties at $24^{\circ} \mathrm{C}$ & Value \\
\hline Density $\left[\mathrm{gm} / \mathrm{cm}^{3}\right]$ & 1.123 \\
\hline Hardness, (shore A/shore D) & $87 / 60$ \\
\hline Tensile strength $\left[\mathrm{N} / \mathrm{mm}^{2}\right]$ & 20.4 \\
\hline Shear strength $\left[\mathrm{N} / \mathrm{mm}^{2}\right]$ & 21.94 \\
\hline Elongation, \% & $475 \%$ \\
\hline
\end{tabular}

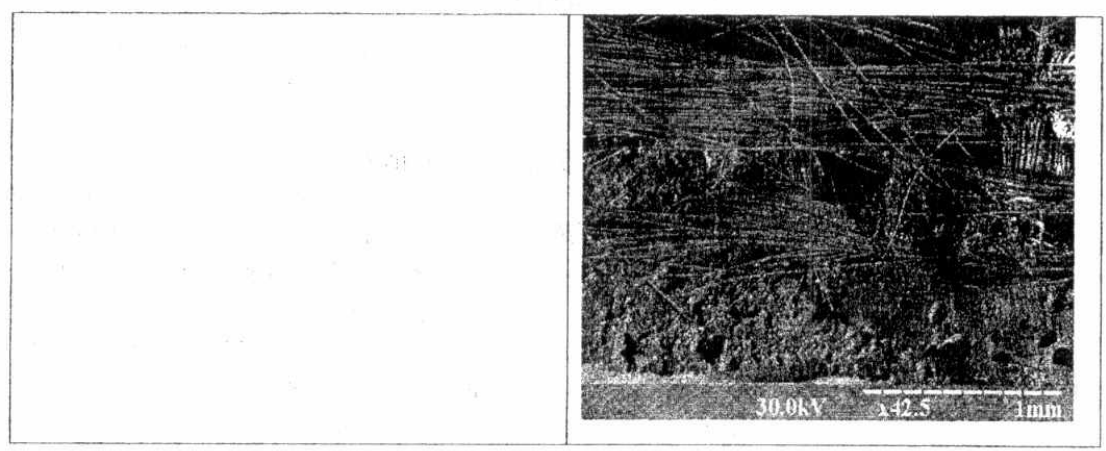

Figure (1) Microscopic photography of produced composite

\section{Preparation of Composite}

The composite used in this study is laminated composite, which consists of layers of Kevlar textile sprayed with layers of polyurea polyurethane on one side. Applying the plolyurea polyurethane layers needs the following equipment: LINE$X$ dispensing equipment Fig. (2), $10 \mathrm{HP}$ compressor $1 \mathrm{~m}^{3} /$ minute, refrigerated air dryer, high temperature/pressure hose, and sprayer gun, shown in Fig. (3). Equipment settings are as follows: Pressure: 10.4-15.2 MPa. Preheated temperatures were for component $(A): 50^{\circ}-60^{\circ} \mathrm{C}$, components $(B): 50^{\circ}-60^{\circ} \mathrm{C}$ and the hose temperature is $50^{\circ}-60^{\circ} \mathrm{C}$. Steps of the process go as follows:

1. Feeding pumps suck the two components separately from the barrels to the LINE-X dispensing equipment Fig. (4).

2. In the LINE-X dispensing equipment the pressure is then increased to the required pressure (10.4-15.2 $\mathrm{MPa})$. 
3. Then the two components were heated separately to $50^{\circ}-60^{\circ} \mathrm{C}$.

4. The two materials were then transferred through the hoses to the sprayer gun.

5. The sprayer gun is then triggered which allows mixing of the two components (1:1 by volume) and also to control the spread of the final material.

6. The required thickness of the LINE-X layer is applied on the Kevlar textile.

7. Then the final composite is cut to $15 \times 15 \mathrm{~cm}$ panels.

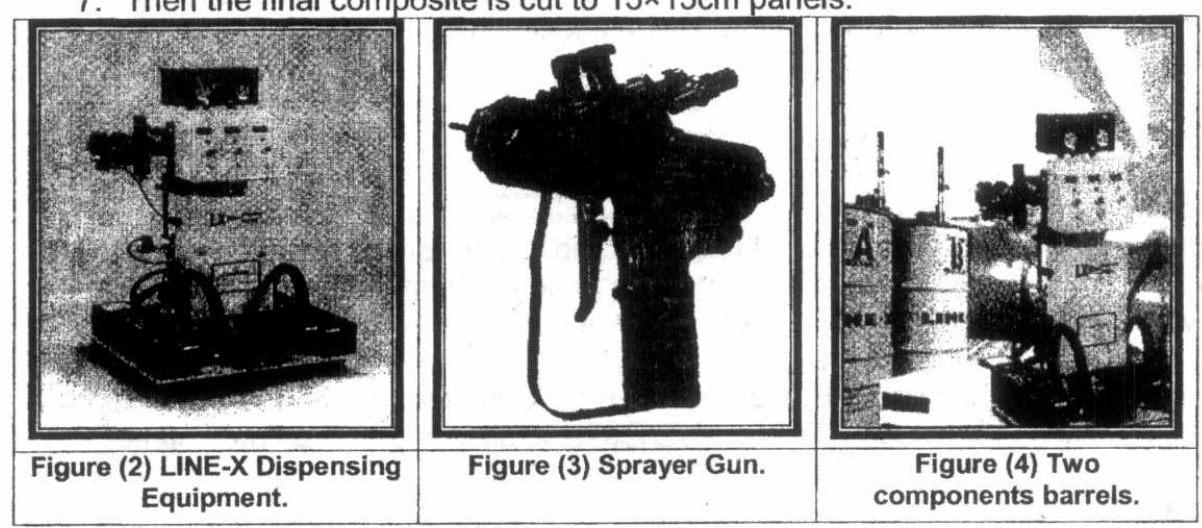

\section{Material Characterization}

In the present work, material characterization was limited to measuring tensile properties of the composite as well as measuring the weight and dimensions of different layers.

The tensile test was performed to determine the strength, ductility and modulus of elasticity of the composite. Many shapes for the specimen were tested. The first try was according to the Standard test methods for textile composite [9].

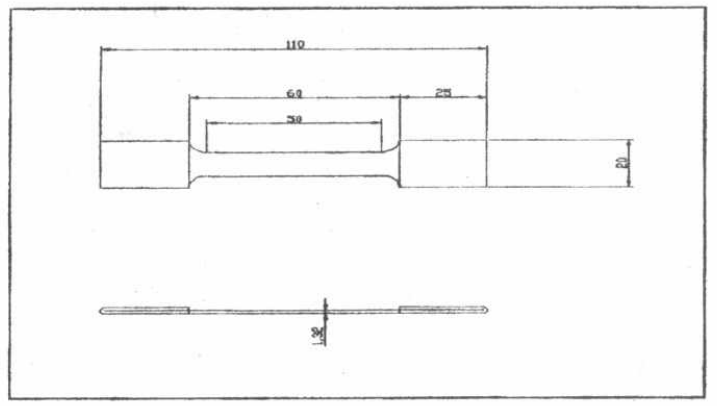

Figure (5) Dimensions of the tensile test specimen. 
The specimen was $(160 \times 20 \mathrm{~mm})$ rectangular and the grip tabs were aluminum. This specimen suffered from slipping of the fibers from the textile structure which gave unreasonable results. The specimen was then improved by decreasing the width of the effective area to $10 \mathrm{~mm}$, but this did not prevent the fiber slippage. Finally to solve this problem the aluminum grips were removed and the grips were then made by folding the ends of the specimen at the textile side and fixing them by epoxy. The proposed tensile test specimen is shown in Fig (5). Tensile test of the manufactured composite was carried out on the universal tensile test machine model ZD 10 of capacity 10 tons, Mechanical engineering branch, M. T. C.

\section{Ballistic Tests and Measurements}

In the ballistic tests performed, measurements were mainly concerned with the determination of the projectile impact and post-perforation velocities for different targets, and with different firing conditions. The problem of velocity measurement was actually converted to the measurement of time at which the projectile took to pass over a fixed distance. This gave an average value of the velocity. Arrival and departure of projectile over predetermined distances could be detected by the breaking or connecting of electric circuits, to start and stop a time counter.

\section{Ballistic setup}

The ballistic experiments were performed in an instrumented ballistic range which has provisions for the measurements of projectile impact and postperforation velocities. Figure (6) is a scheme of the test arrangement [7].

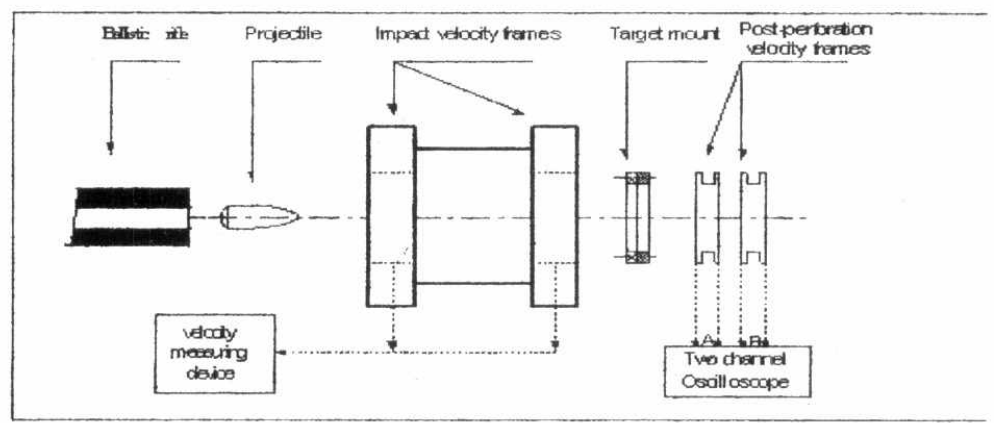

Figure (6) Scheme of ballistic set-up

\section{RESULTS AND ANALYSIS}

\section{Material Characterization}

The general assumption that fabric behavior is linearly elastic up to fracture has also been used by many investigators, e. g. Lim et al. [10]. By this simplification 
the behavior of the material can be described by two parameters, the fracture strength and the corresponding fracture strain. Simply then the modulus of elasticity can be calculated by getting the slope of the stress strain curve. The tensile properties of the Kevlar-129 were taken from the data sheet [11], and the tensile properties of the LINE-X xs-350 were taken from the data sheet, of the company. The main properties are listed in Table (2) and Table (3) respectively.

Table (2) Tensile properties of Kevlar 129 [11].

\begin{tabular}{|c|c|c|c|}
\hline $\begin{array}{c}\text { Density, } \boldsymbol{\rho} \\
{\left[\mathrm{kg} / \mathrm{m}^{3}\right]}\end{array}$ & Strength, [GPa] & Strain[\%] & $\begin{array}{c}\text { Modulus of } \\
\text { Elasticity, [GPa] }\end{array}$ \\
\hline $1.45 \times 10^{3}$ & 3.4 & 4.4 & 143 \\
\hline
\end{tabular}

Table (3) Tensile properties of LINE-X xs-350.

\begin{tabular}{|c|c|c|}
\hline Density, $\rho,[\mathrm{kg} / \mathrm{m} 3]$ & Strength, [MPa] & Strain, [\%] \\
\hline $1.123 \times 10^{3}$ & 20.4 & 475 \\
\hline
\end{tabular}

Then the tensile properties of the manufactured composite were measured. The results of the tensile test are listed in Table (4)

Table (4) Tensile properties of composite used.

\begin{tabular}{|c|c|c|}
\hline Strength [MPa] & Strain, [\%] & $\begin{array}{c}\text { Modulus of } \\
\text { Elasticity, [MPa] }\end{array}$ \\
\hline 646.39 & 14 & 4617 \\
\hline
\end{tabular}

The weight per unit area, areal density, was measured for one layer of both Kevlar 129 and composite Kevlar/LINE-X. Kevlar areal density was equal to $0.6411 \mathrm{~kg} / \mathrm{m}^{2}$, whereas composite areal density was equal to $1.6214 \mathrm{~kg} / \mathrm{m}^{2}$.The properties are listed in Table (5).

Table (5) Properties of Kevlar 129 textile, LINE-X and composite layer.

\begin{tabular}{||c|c|c|c||}
\hline Property & $\begin{array}{c}\text { Kevlar 129 } \\
\text { textile layer }\end{array}$ & LINE-X & $\begin{array}{c}\text { Composite } \\
\text { layer }\end{array}$ \\
\hline Density, $\left[\mathrm{kg} / \mathrm{m}^{3}\right]$ & $1.45 \times 10^{3}$ & $1.123 \times 10^{3}$ & $1.233 \times 10^{3}$ \\
\hline $\begin{array}{c}\text { Areal density } \\
{\left[\mathrm{kg} / \mathrm{m}^{2}\right]}\end{array}$ & 0.6411 & & 1.6214 \\
\hline Volume fraction & 0.336 & 0.664 & \\
\hline Weight fraction & 0.3954 & 0.6046 & \\
\hline
\end{tabular}




\section{BALLISTIC FIRING TEST RESULTS}

\section{Determination of Projectile impact and residual velocities}

The impact velocity was controlled by changing the mass of propellant charge. A set of projectiles with different propellant charges was fired against each target. The projectiles impact and residual velocities were measured using the velocity measuring system that has mentioned above.

\section{Results of Kevlar Targets \\ Effect of projectile impact velocity}

Figure (7) illustrates the change of the residual velocity $v_{r}$ with the impact velocity $v_{i}$. Best regression lines were used to fit the results. The figure shows that for each target the residual velocity increases with the increase of impact velocity in a quasi-linear manner over the used range of velocity. Similar results were obtained by Resnyansky and Katseil [12]; they fired ball projectiles on carbon fiber targets of thickness $1.5,3,4.5$ and $6 \mathrm{~mm}$ in the velocity range from $280 \mathrm{~m} / \mathrm{s}$ up to $970 \mathrm{~m} / \mathrm{s}$.

The change of the velocity drop, $\Delta v=v_{i}-v_{r}$, with the impact velocity is represented in Fig. (8). It can be seen from the figure that the velocity drop decreases continuously by the increase of the projectile impact velocity for each target. This trend was maintained at all impact velocities considered, indicating that no change in the failure mechanism is likely to have taken place.

The relation between the projectile impact energy $E_{i}$ and the projectile residual energy $E_{r}$ is represented in Fig. (9). It is found that for each target the residual projectile energy increases by the increase of the impact energy.

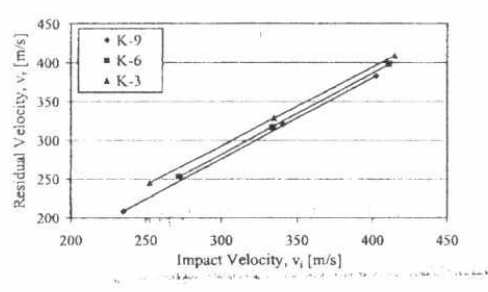

Fig. (7) Measured residual velocity versus impact velocity for Kevlar targets with different number of layers.

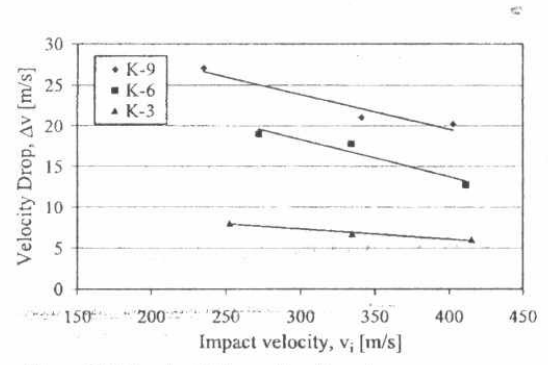

Fig. (8) Projectile velocity drop versus impact velocity for Kevlar targets with different number of layers 


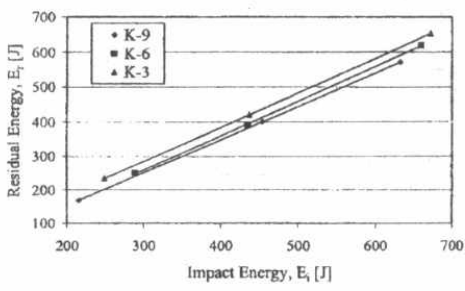

Fig. (9) Change of projectile residual energy with impact energy for Kevlar targets with different number of layers.

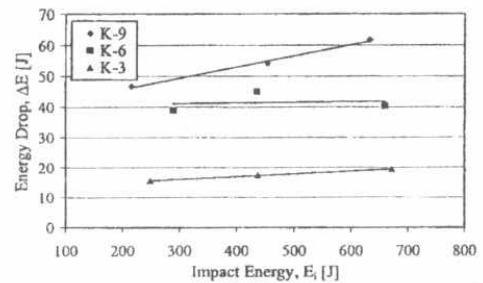

Fig. (10) Change of target absorbed energy with projectile impact energy for Kevlar targets with different number of layers.

The energy absorbed during the target penetration $\Delta \mathrm{E}$ was calculated as the difference between the projectile impact and residual energies. Figure (10) represents the change of the energy absorbed by the target with the projectile impact energy. The figure shows that the trend of energy absorbed by each target increases with the increase of the impact energy. These results are in agreement with those of Fayed [7], who tested 3D weave ${ }^{\mathrm{TM}}$ Kevlar-129/Epoxy and S-2 Glass/Epoxy targets against the impact of $7.62 \mathrm{~mm}$ projectile at the range of velocities from $220 \mathrm{~m} / \mathrm{s}$ up to $580 \mathrm{~m} / \mathrm{s}$.

\section{Effect of number of layers}

In the following, the ballistic resistance of the tested Kevlar 129 targets is evaluated through studying the effect of number of layers on the velocity drop $\Delta v$, the absorbed energy by the target $\Delta \mathrm{E}$.

Figure (11) depicts the change of the velocity drop with the target number of layers at the impact velocities $v_{i}=253$ and $408 \mathrm{~m} / \mathrm{s}$. The figure shows that the velocity drop increases by increasing the number of layers.

The effect of number of layers on the energy absorbed is shown in Fig. (12). It can be seen that the trend of energy absorbed by the target increases by adding more Kevlar layers to the target. Dividing the energy absorbed by the target by the number of target layers, one gets the average energy absorbed by one layer, as shown in fig. (12).

It is clear that this "specific" energy also increases with number of layers, a result which has been obtained by many investigators for almost all types of targets, e. g. $[14,15]$. 


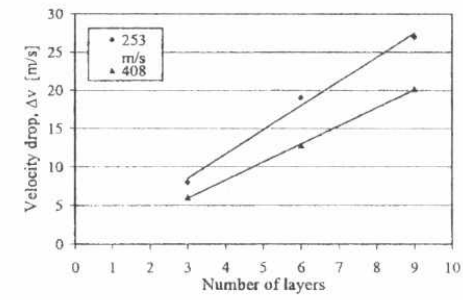

Fig. (11) Projectile velocity drop versus Kevlar target number of layers at $v_{i}=253$ and $408 \mathrm{~m} / \mathrm{s}$.

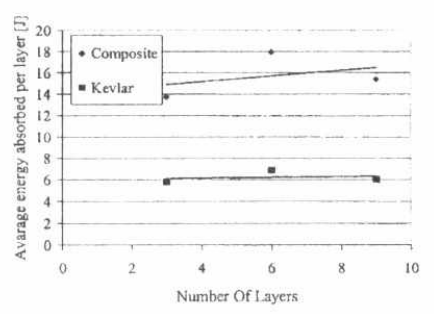

Fig. (12) Energy absorbed by Kevlar and Composite targets versus target number of layers.

\section{Results of Composite Kevlar/LINE-X Target Effect of projectile impact velocity}

The same parameters chosen to evaluate the ballistic resistance of the $\mathrm{K} / \mathrm{L}$ composite targets are the same as those used in the preceding section. Fig. (13) presents the relation between the residual velocity $v_{r}$ and the impact velocity $v_{i}$. This relation is in general similar to that of the Kevlar targets; the residual velocity increases with the increase of the impact velocity.

The relation between the impact velocity and the velocity drop during penetration is shown in Fig. (14). It is seen that the velocity drop during penetration decreases as the impact velocity increases. In Fig.(15) the residual energy $E_{r}$ increases by the increase of the impact energy, which is similar to the behavior of the Kevlar targets. In Fig.(16), however, the energy absorbed $\Delta E$ behaves in a different manner. It increases by the increase of the impact energy $E_{i}$.

From the previous relations it can be seen that the composite behaves qualitatively like the Kevlar fabric in resisting the projectiles. Based on this similarity, one can anticipate that the failure modes of the Kevlar/LINE-X composite and the Kevlar fabric are most likely the same. This is probably because the Kevlar fabric is the effective constituent of the composite in ballistic resistance, in agreement with Bohong Gu [13], how tested two kinds of multilayered plain fabric targets made of Twaron and Kuralon fibers.

\section{Effect of number of layers}

Following, the ballistic resistance of the composite targets is evaluated by studying the effect of increasing the number of layers on the velocity drop $\Delta v$, and absorbed energy $\Delta \mathrm{E}$. Two impact velocities were selected for this study. The first one is $323 \pm 18 \mathrm{~m} / \mathrm{s}$, denoted by $323 \mathrm{~m} / \mathrm{s}$. The second one is $414.6 \pm 21 \mathrm{~m} / \mathrm{s}$, denoted by $414 \mathrm{~m} / \mathrm{s}$. The velocity drop increases by the increase of number of layer for both impact velocities. This result is described in Fig. (17). Fig. (18) 
Shows the energy absorbed by the target as it changes with the number of layers. Also, the absorbed energy increases by adding more layers of the used composite.

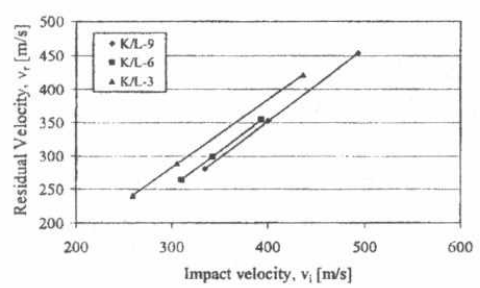

Fig. (13) Measured residual velocity versus impact velocity for different number of layers of composite targets.

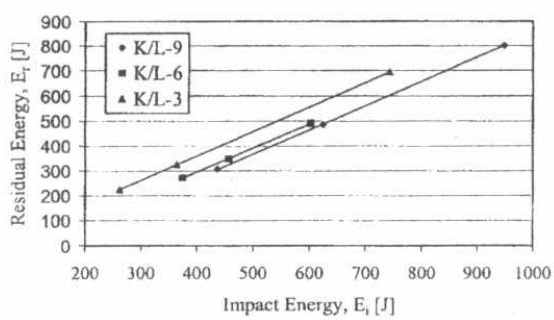

Fig. (15) Change of projectile residual energy with impact energy for different number of layers of composite targets.

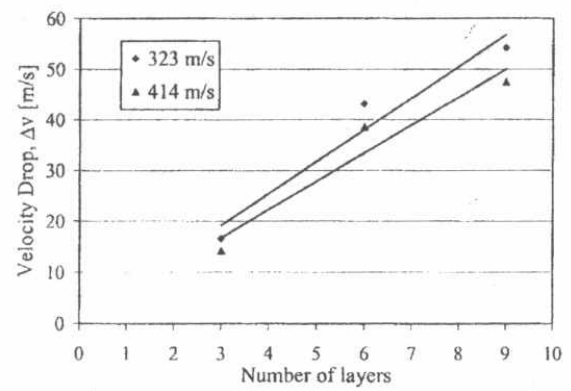

Fig. (17) Projectile velocity drop versus composite target number of layers at $v_{1}=323$ and $414 \mathrm{~m} / \mathrm{s}$.

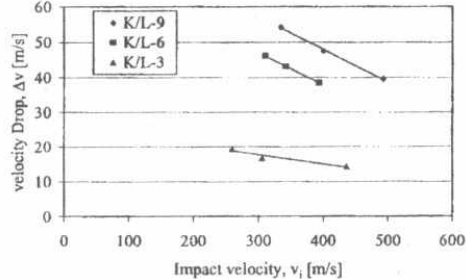

Fig. (14) Projectile velocity drop versus impact velocity for different number of layers of composite targets.

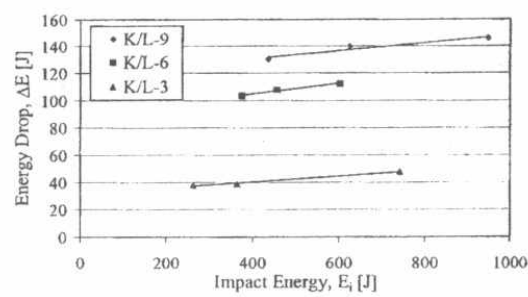

Fig. (16) Change of energy absorbed by target with projectile impact energy for different number of layers of composite targets.

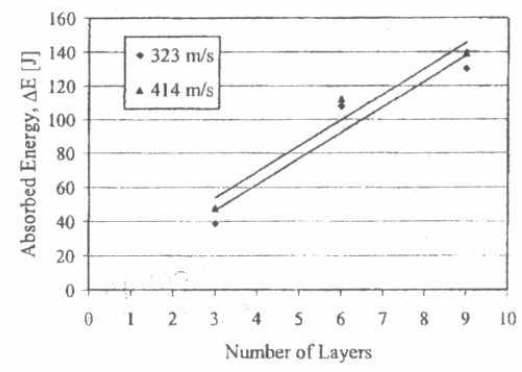

Fig. (18) Target absorbed energy versus composite target number of layers at $v_{1}=323$ and $414 \mathrm{~m} / \mathrm{s}$. 


\section{Post Firing Examinations i) For kevlar targets}

Figures (19) and (20) show photographs of the front and back face of six-layer and nine-layer Kevlar targets. The failure mode of these targets is tensile failure. The yarns of the textile were subjected to high strain during projectile penetration and stretched to failure. The figures show also that the damage was not localized. The formed bulge after penetration was rhombus. This agrees with Leech, et al [1].The area which affected by the plastic deformation in case of the nine-layer target was smaller than that of the six-layer target. This indicates that adding more layers to the target gives the target additional resistance rather than fiber tension. In other words, the rear layers back-up the front ones.

\section{ii) For composite targets}

Figure (21) and (22) show photographs of front and back face of six-layer and nine-layer composite targets. The failure mode of these targets is the same as that of the Kevlar targets, that is, tensile failure. This can be noticed from the exit of the projectile; no plugging to the target material can be found after firing. The damaged area of the composite targets is rather localized. This may be attributed to the flexibility presented to the fabric by adding the LINE-X layer to it.

\section{CONCLUSIONS}

The performance of the new composite is promising; the specific energy absorbed by the composite targets is always higher than that absorbed by the Kevlar targets. In case of Kevlar targets, and the mean impact velocities of $425 \pm 10 \mathrm{~m} / \mathrm{s}, 402 \pm 10 \mathrm{~m} / \mathrm{s}, 400 \mathrm{~m} / \mathrm{s}$ the average energy absorbed per one layer is for $\mathrm{K}-3=6.43 \mathrm{~J}, \mathrm{~K}-6=6.71 \mathrm{~J}$ and for $\mathrm{K}-9=6.86 \mathrm{~J}$ respectively. This means that by increasing the target number of layers the ability of one layer to absorb energy increases. Similarly, in case of Kevlar/Line-x targets, based on the results of the same impact velocities Kevlar targets mentioned above, average energy absorbed per one layer is for $\mathrm{K} / \mathrm{L}-3=15.8 \mathrm{~J}, \mathrm{~K} / \mathrm{L}-6=18.7 \mathrm{~J}$ and for $\mathrm{K} / \mathrm{L}-9=15.5 \mathrm{~J}$ respectively. Moreover, post firing examinations of Kevlar/line-x targets show recoverable behavior and localized damage after the ballistic impact; this indicate less trauma effect in case of using this composite as body armour material. 


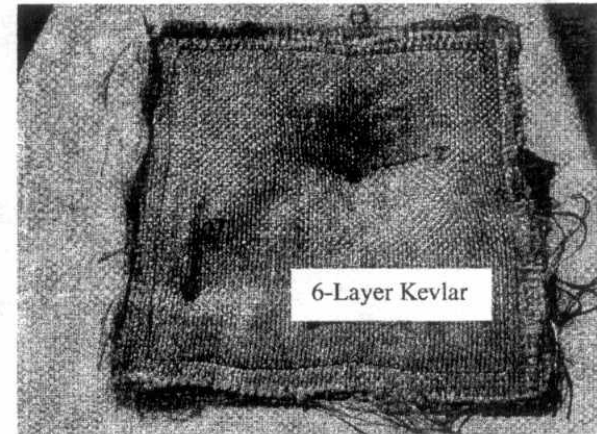

(a)

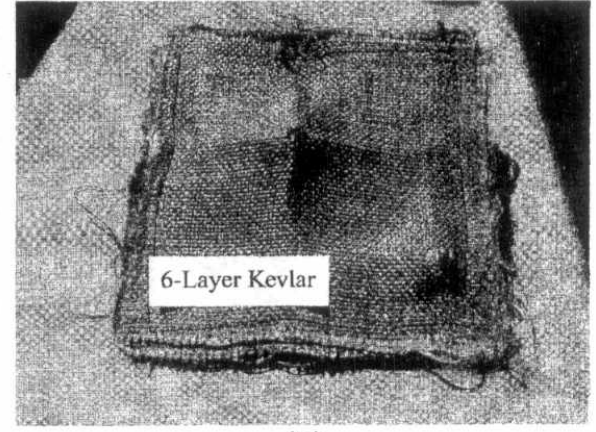

(b)

Fig (19) A K-6 target perforated by 7.62 projectiles with different velocities at normal impact: (a) front face, and (b) back face

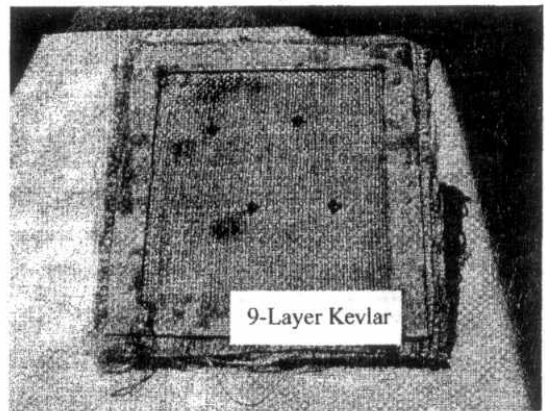

(a)

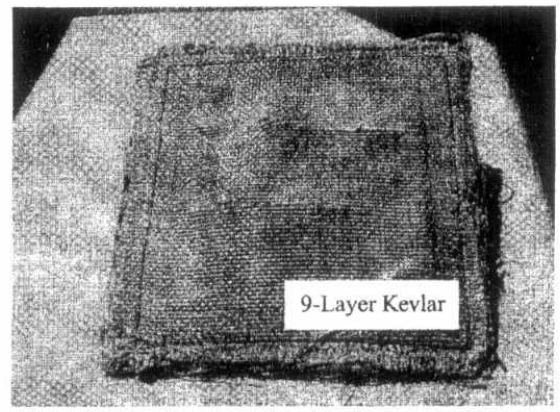

(b)

Fig (20) A K-9 target perforated by 7.62 projectiles with different velocities at normal impact: (a) front

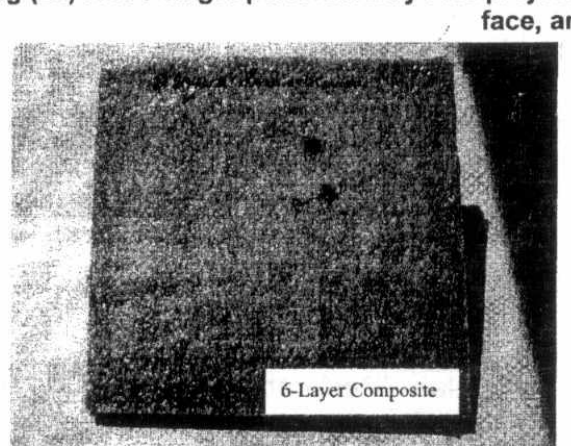

(a)

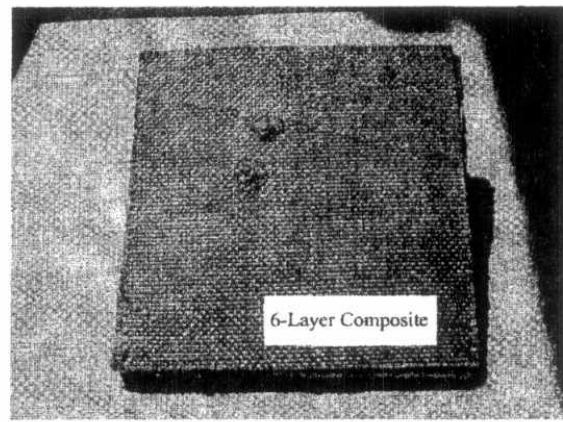

(b)

Fig. (21) A K/L-6 target perforated by 7.62 projectiles with different velocities at normal impact: (a) front face, and (b) back face 


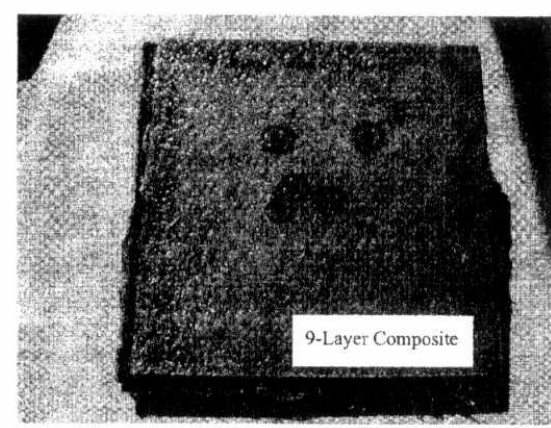

(a)

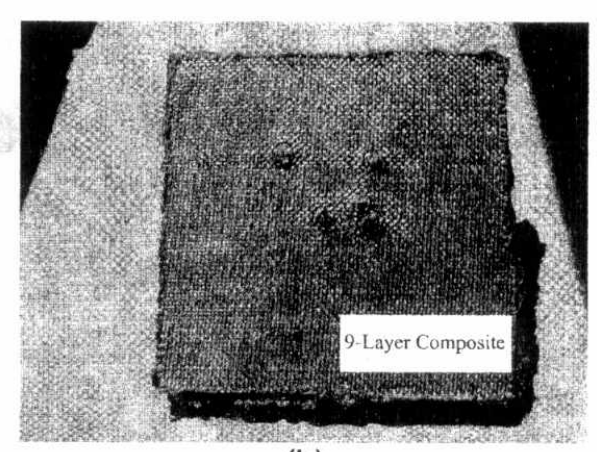

(b)

Fig. (22) A K/L-9 target perforated by 7.62 projectiles with different velocities at normal impact: (a) front face, and (b) back face

\section{REFERENCES}

1. C.M. Leech, J. W. S. Hearle, and J. Mansell, 'A Variational Model for the Arrest Projectiles by Woven Cloth and Nets', J. of Textile Institute, No.11, pp. 469-478, (1979).

2. G. Zhu, W. Goldsmith, and C.K.H. Dharan, 'Penetration of Laminated Kevlar by Projectiles-II. Theoritical investigation', Int. J. Solid Structures, Vol. 29, No. 4, pp. 421-436, (1992).

3. V.P.W. Shim, C.T. Lim, and K.J. Foo, 'Dynamic mechanical properties of fabric armor' Int. J. of Impact Engng., vol. 25, pp. 1-15, (2000).

4. James D. Walker, 'Ballistic Limit of Fabrics with Resin', $19^{\text {th }}$ Int. Symp. on Ballistics, vol. 3, pp. 442-453, USA, (2001).

5. E. DeLuca, j. Prifti, W. Betheney and S. C. Chou, 'Ballistic Impact Damage of S2-Glass-Reinforced Plastic Structural Armor', Composite Science Technology, vol 58, pp. 1453-1462, (1998).

6. H. H. Billon, and D. J. Robinson, 'Models for the Ballistic Impact of Fabric Armor', Int. J. of Impact Engng., vol. 25, pp. 411-422, (2001).

7. A. I. Fayed, A. M. Raid, and S. A. Salah, 'Perforation of a Small Caliber Projectile into Textile/Epoxy Composite Targets', $10^{\text {th }}$ International Conf. on Aerospace Science \& Aviation Technology, Proc. $10^{\text {th }}$ ASAT Conf, M. T. C., Cairo, 13-15 May, (2003). 
8. K. J. Knox, Michael I. Hammons, Timothy T. Lewis and Jonathan R. Porter, 'Polymer Materials for Structural Retrofit', Air Expeditionary Forces Technology Division, NASA-19000, Sept.(1996).

9. J. E. Masters, and M. A. Portanova, 'Standard Test Methods for Textile Composites', Material Technology Division, NASA-19000, Sept.(1996).

10. C. T. Lim, V. P. W. Shim, Y. H. Ng, 'Finite-Element Modeling of the Ballistic Impact of Fabric Armor', Int. J. of Impact Engng., vol. 28, pp. 1331, (2003).

11. H. H. Yang, 'Kevlar Aramid Fiber', John Wiley\&sons Ltd. Chichester, England, (1993).

12.A. D. Resnyansky and G. Kataselis, 'Penetration Equations for Normal and Oblique Impact of Small Arms Projectiles Against Carbon-Fiber Composite', $21^{\text {st }}$ Int. Symp. of Ballistics, pp. 1411-1423, Sidney, (2004).

13. Bohong Gu, 'Analytical Modeling for the Ballistic Perforation of Plannar Plain-Woven Fabric Target by Projectile,' Composites: Part B 34, pp.361371, (2003).

14. Abdel-Kader M. S., 'Effect of Projectile Impact Velocity and Target Thickness on Penetration Resistance of Mild Steel', Proc. $4^{\text {th }}$ ASAT Conf., M.T.C., Cairo, 14-16 May, (1991).

15. Almohandes A. A., Abdel-Kader M. S., and Eleiche A. M., 'Ballistic Performance of Single and Laminated Mild Steel Plates', Proc. AMME-6 Conf., M.T.C., Cairo, 3-5 May,1994. 